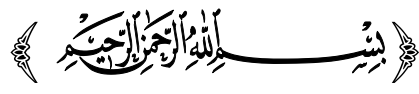

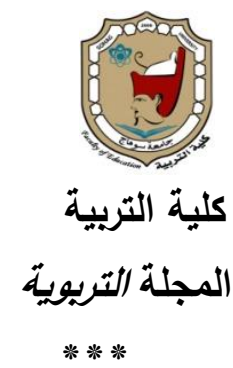

$$
\begin{aligned}
& \text { الهمان في همال النمت عبر الهمصر } \\
& \text { "دراسة تمالية" } \\
& \text { lal } \\
& \text { أ. عبد الرحمن حسن عواض عرابي } \\
& \text { معيد بقسم التربية الفنية } \\
& \text { كلية التربية النوعية - جامعة جنوب الوادي }
\end{aligned}
$$

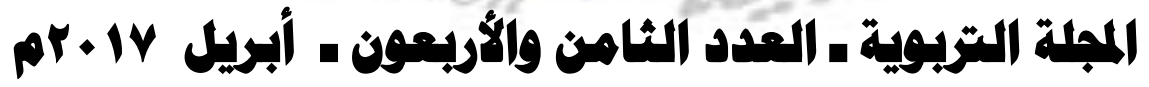

Print:(ISSN 1687-2649) Online:(ISSN 2536-9091) 
تناول الغالبية العظمي من فناني التاريخ العظام كالفنانين والثعراء و الرسامين أو

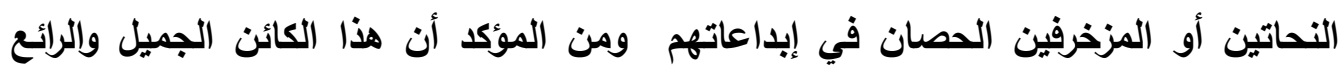

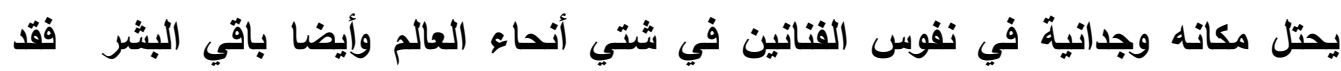

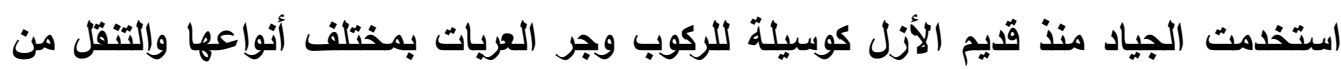
مكان لآخر ، وإذا عدنا إلي الوراء كثيرا أو قليلا إلي عصور الإمبراطوريات القديمة أو إلى إلي التيات

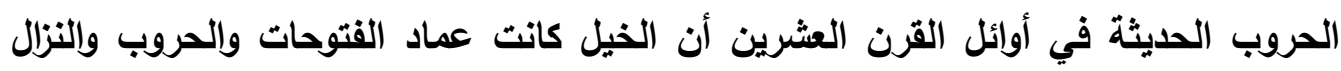

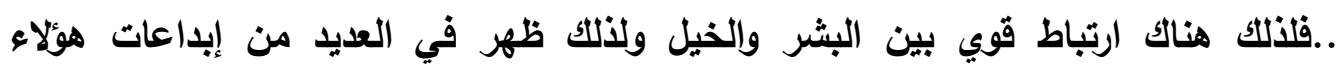

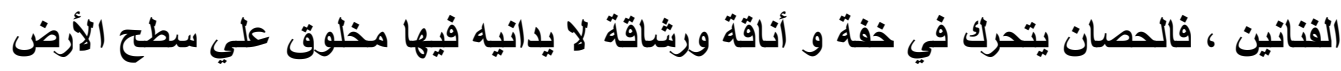

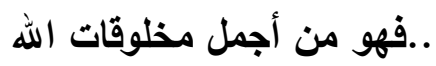

لأن الله سبحانه وتعالي صاغه علي هيئة من جمال وتتاسب لا تداني ، وجمع فيه بين الرقة والصلابة علي نحو يدعو إلي الإعجاب والعجب ، فإنتك تراه بهيبته الرفيعة الرشيقة فيخيل إلي

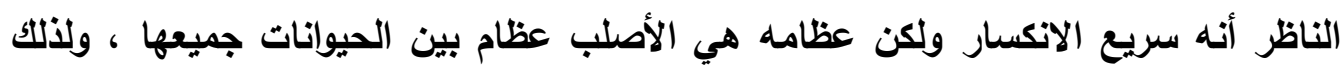
فهو عدوه يضرب الأرض مختالا واثثا فتحسبه يطير طيراناً ... وليس في الانيا منظر حيوان الأنيان

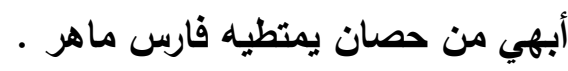
هناك العديد من فصائل وأجناس الحصان والتي يأتي الحصان العربي الأصيل علي قائمة

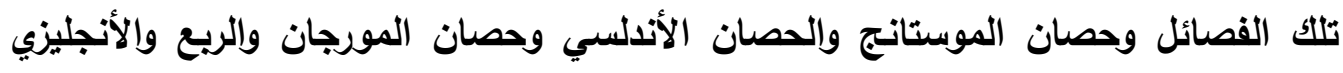
وغيرها من أنواع ذلك المخلوق الجميل .

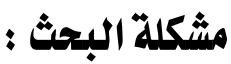

تمحورت مشكلة البحث في الدراسة التحيلية للحصان عبر العصور المختلفة والقيم الجمالية والتثكيلة المميزة له، والكثف عن أهمية الرسوم التحضيرية قبل تنفيذ العمل العله النحتي.

فرض البحث : ان

يفترض هذا البحث أن الحضارات التي تناولت الحصان والخيول في إبداعتهم علي مر فر

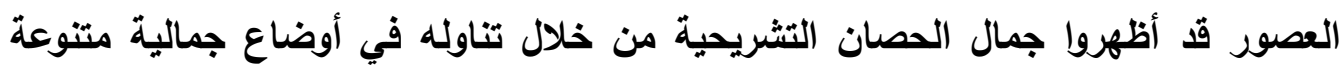




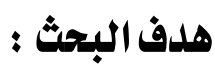

يهاف البحث إلي إبراز الأهمية التشريحية للحصان في العديد من الأعمال الفنية في العضارات والعصور المختلفة كعنصر هام في العمل الفني .

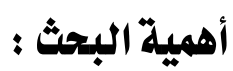

- يعد الحصان أحد أجمل الكائنات التي خلقها الله عزو جل ،قفيه العديد من الصفات والخصائص التي تجطله علي رأس الحيوانات جمالاً ،حيث تلك الصفات التشريحية الدقيقة التي تحفز الإنسان لتناوله في الأعمال الفنية المختلفة والذي ظهر في الكثير من الموضوعات والأعمال في مختلف الحضارات .

- يهتم البحث بالجانب التريوي التعليمي من خلال توظيف ما توصل إليه الباحث من أهمية للجانب التشريحي للحيوانات (الحصان كمثال ) عبر العصور المختلفة وأهتمام الفنانين بها في تنمية مهارات طلاب كليات التربية النوعية - قسم التربية الفنية في مجال النحت .

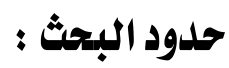

يتعرض البحث بالدراسة الفنية التحليلية المتعلقة بالنواحي التشريحية للحصان في مختلف الحضارات كالحضارة المصرية القديمة وإلحضارة اليونانية والرومانية والعصر الحديث. بالنوانية منهج وإجراءات البحث : يتبع البحث المنهج الوصفي التحليلي ،"هو المنهج الأي يعتمد على الدراسة الظاهرة

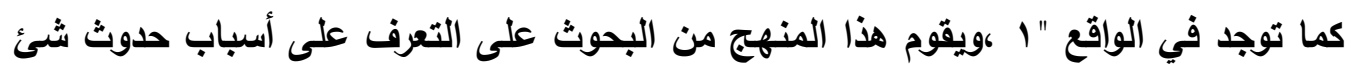

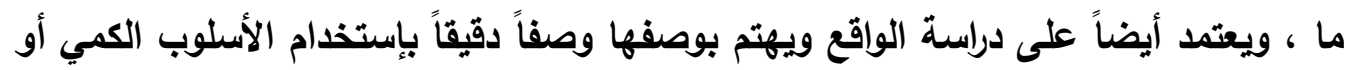
الكيفي ، ويقتصر الأسلوب الوصفي على جمع المعلومات وتتظيمها بهدف فهم واقع الظاهرة كما هو ومن ثم الوصول إلي أستنتاجات وتعميمات لتطوير موضوع الظاهرة كما هو الحال من

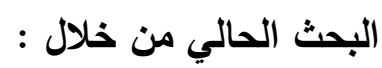
- الإطلاع على البحوث والدراسات السابقة والتي لها علاقة بموضوع الدراسة . . - دراسة تحليلية تشريحية شكل الحصان في العصرالمصري القديم واليوناني والروماني

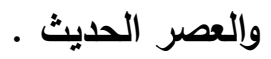

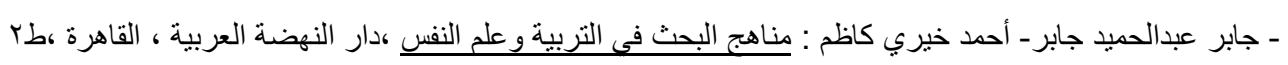

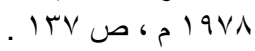


الحصان في مجال النحت عبر العصور "دراسة تحليلية".

الدراسات وأبحاث مرتبطة بموضوع البحث :

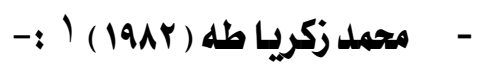

تناولت الدراسة علاقة الانسان بالحصان على مر العصور ،وإستخدام الحصان في

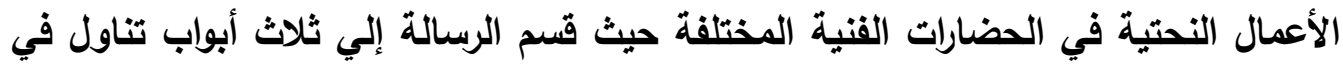

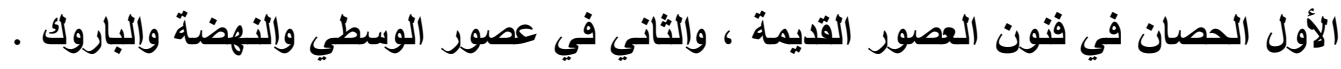

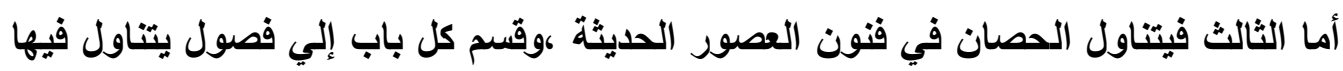

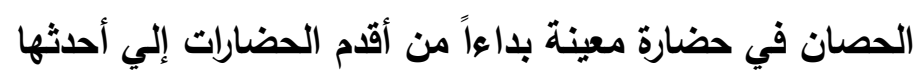

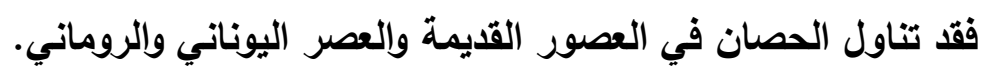

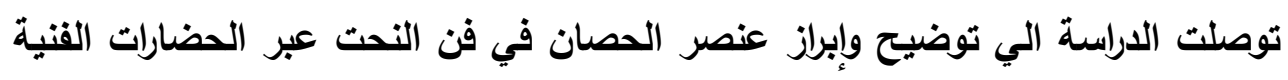
وكيف تناوله الفنان من خلال موضوعات الحروب والصيد. - دراسة أمجلد صلاح اللين التهامي (1999 ) ب :-

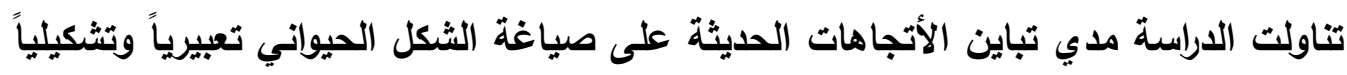

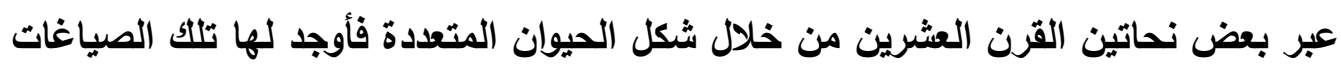
الجديدة من موضوعات تعكس تنوع المفاهيم والاتجاهات الفكرية والقلسفية التي تعاقبت خلال

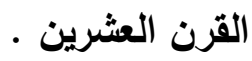

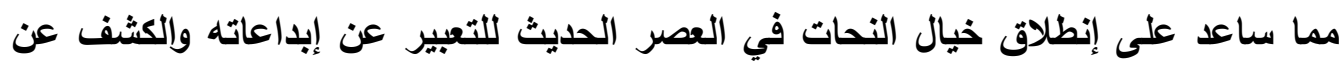

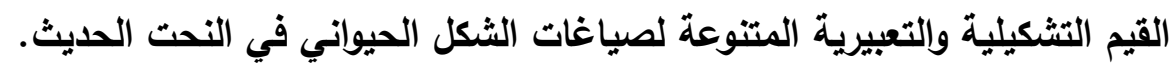

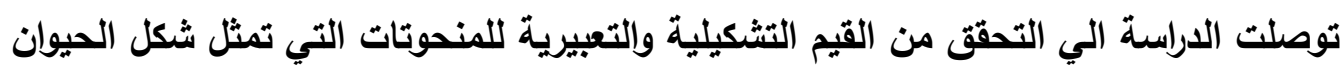
في الفن الحديث جماليات مميزة في اطار النحت المعاصر.

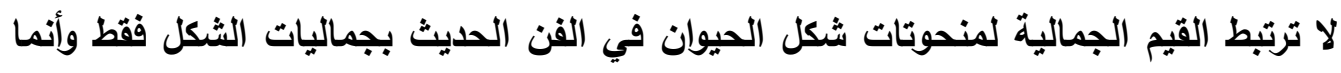

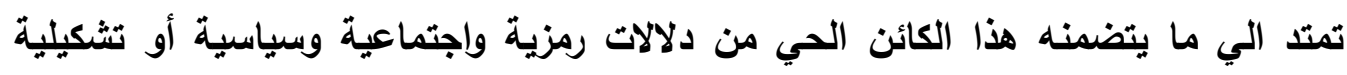
بحته . بل.

'ـ محمد زكريا طه : " الأنسان و الحصان كوحدة تثكيلية عاكسة للقيم انسانية عبر التاريخ "برسالة ماجستير ، كلية الفنون

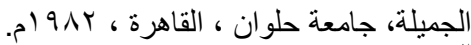

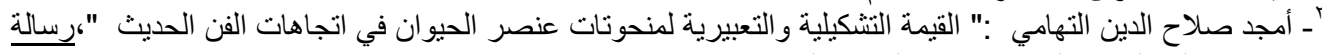

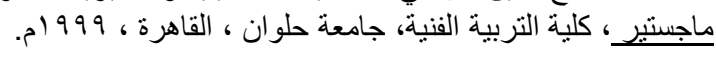




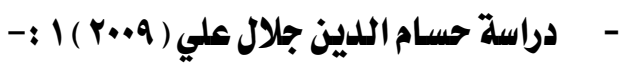

تناولت الدراسة تحليل مفردة الحصان داخل الأعمال القنية عبر الحضارات ، وكيفية استخلاص الأساليب القنية والأستفادة منها في إثراء مجال التصميمات الزخرفية ، وأيضا الامكانات التعبيرية والخصائص التشكيلية والمعطيات الجمالية للحصان كعنصر تشكيلي في

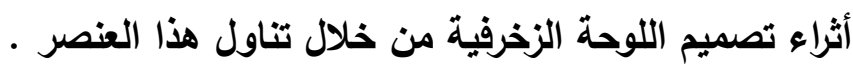
أيضا تناول الحصان بصفة تفصيلية عبر الفصل الثاني عن تاريخ الحصان ونشأته وعلاقته بالإنسان على مر العصور وذلك من خلال ارتباط الحصان بكل النواحي الإجتماعية

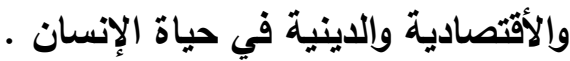

توصلت الدراسة إلي الكثف عن القيم القنية والتعبيرية والخصائص الجمالية لعنصر الحصان والكثف ايضا عن أساليب تثاول هذا العنصر كمفرده تشكيلية عبر القنون القديمة والحديثة وطرق صياغاتها تشكيليا. والأفادة من السمات الشكلية والجمالية للحصان كمفردة في أثراء تصميم اللوحة الوحة الزخرفية تثكيلياً وجمالياً وتعبيرياً.

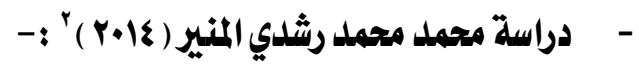

تناولت الاراسة إظهار أهمية الحصان في معظم الأعمال القنية القديمة كعنصر أساسي في بناء العمل الفني، وتحقيق الموضوع الذي يهاف اليه ذلك العمل ، كما يلقي الضوء على الضى بعض الفنانين الذين عثقوا هذا الحيوان وتتاولوه في كثير من أعمالهم الجرافيكية مع تحليل فني لتتلك الأعمال ،واظهار العلاقة بين الجمال والحركة في الحصان وإنعكاسها في إخراج عمل فني على أعلى مستوي من الأبداع. توصلت الدراسة إلي إظهار جمال ورشاقة جسم العصان وحركاته المتنوعة من خلال الفنانين الذين تناولوه في إبداعاتهم وذلك على مر العصور، وتوضيح المدي الفني والإبداعي في إظهار الجمال والحركة في تناول الحصان في بعض الأعمال الجرافيكية بالأبيض والأسود في تحقيق ذلك المضمون.

'ـ جسام الدين جلال :" الحصان كمفردة تشكيلية عبر الحضار ات الفنية كمدخل لإثر اء الجو انب الجمالية و التعبيرية في

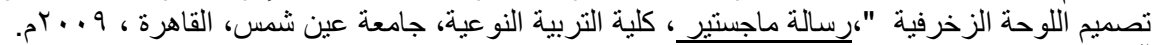

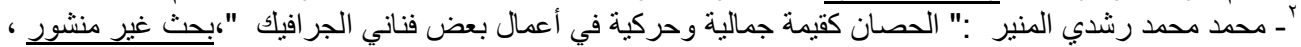

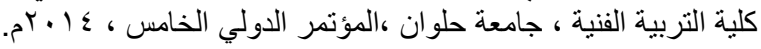


لم تخل أي حضارة أو عصر من العصور المختلفة البعيد منها أو حتي القريب من الأعمال القنية التي أحتوت على الحصان في أعمال نحتية مجسمة أو جدارية أو رسوم ونقوش على جدران المعابد أو الكهوف القديمة والمرور بالعصور الوسطي والنهضة والتفن التمان الحديث ووصولاً إلي وقتنا هذا مما قد يبرهن على أن الحصان لديه مقاومات جمالية وتعبيرية غاية في الجمال والروعة مما جذبت هؤلاء الفنانين من مختلف العصور والأزمنة لتناوله بصور عديدة ومتنوعة، فمنذ آلاف السنين تناوله القنان المصري القديم في كثير من أعماله

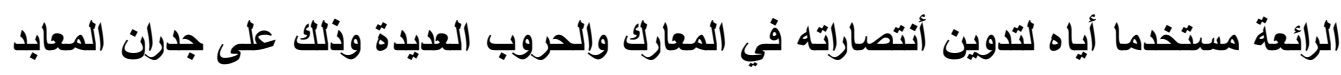

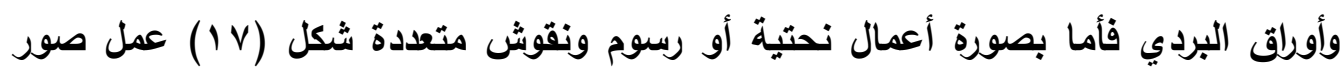

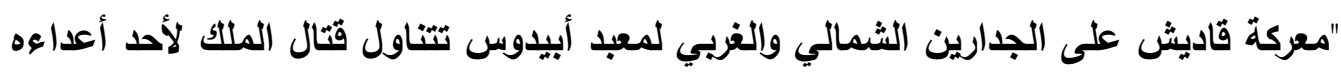
والذبحة التي يلتحم فيها الجيشان في منظر فريد "ا، وأذا نظرنا لذلك العمل نجد أن الفنان

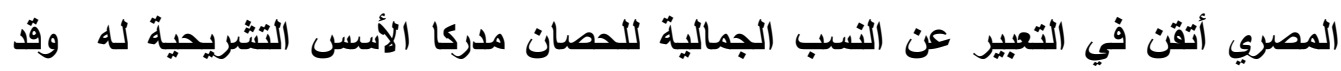
أختار الفنان المصري الوضع ذو الأستطالة للحصان الذي يعتبرا أحد أروع الأوضاع الجمالية

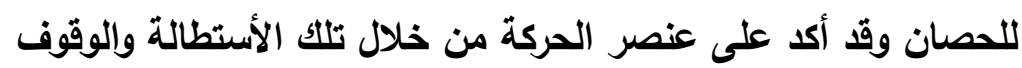

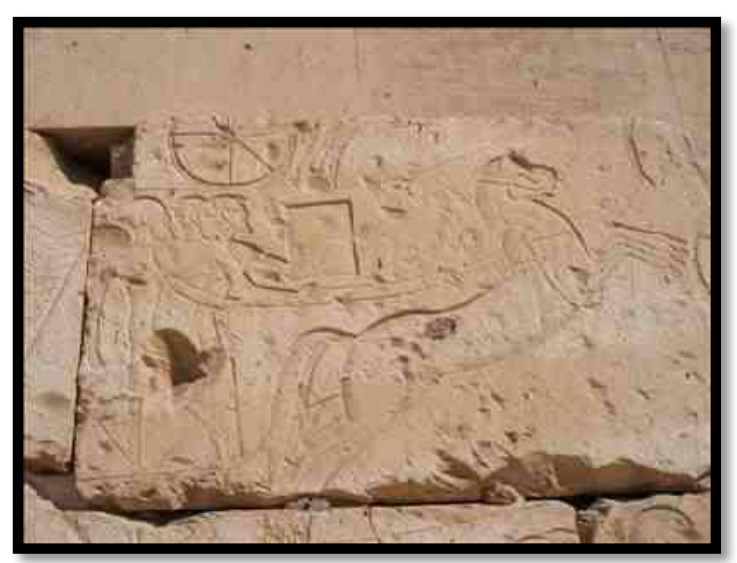

شكل (1 ) نهاية عصر معركة قادش للملك رمسيس الثاني والحيثيين معبد رمسيس الثاني بأبيدوس - "تصوير الباحث" فئه 


\section{الحصان في مجال النحت عبر العصور "دراسة تحليلية".}

مما قد يبرهن على أن الحصان أجتذب ذلك الفنان لما فيه من قيم تثريحية ونسب

$$
\text { جمالية متنوعة . }
$$

ثانياً :الحصان في الحضارة اليوناني ( الأغريقي ) :

لم يقتصر ظهور الحصـان في الحضارة المصرية القديمة فقط بل في الحضارة الساسانية الفارسية وأيضا الحضارة اليونانية والرومانية فقد تناول الفنان الأغريقي أو اليوناني الحصان في كثير من موضوعاته والتعبير عنه في العديد من نقوشاته ومنحوتاه الخلباة ،وقد زين الفنان الاغريق واجهات معابده بنقوش النحت البارز لحصان ،وفي تماثيله الكاملة التي صنعت من البرونز أو الرخام والأمثلة علي ذلك كثير منها في شكل (r)نري لوحة من النحت البارز تمثل الإحتفال الباناثينيكي بمعبد البارثينون بأثينا ،"وقد قام بعمل هذة الته اللوحة الفنان فيدياس ،من الرخام حيث نري فيها فرسانا يركبون الخيول التي نراها في حركة

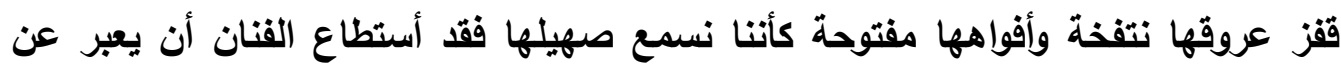
خيل حية ،وقد حاول الفنان ملئ كل مساحة اللوحة بعناصرها مستغلا في ذلك حركات قفز

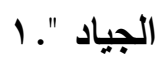

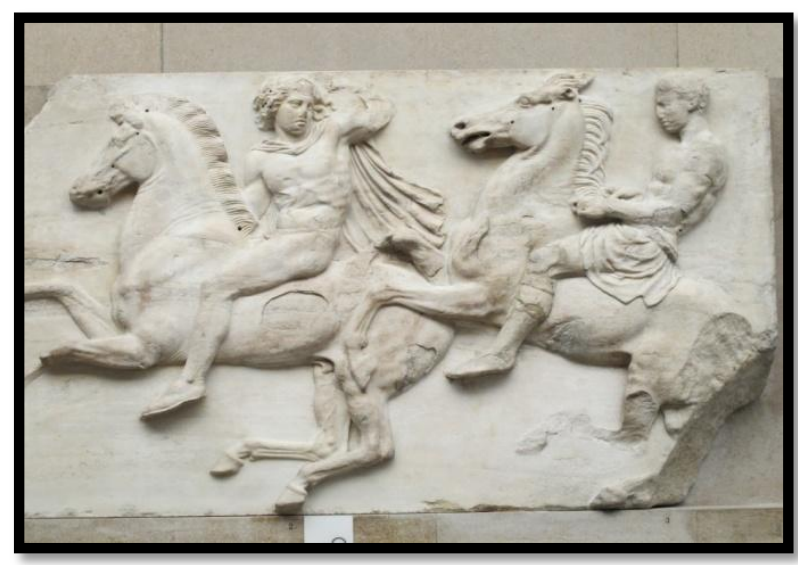

$$
\begin{aligned}
& \text { شكل (Y) يجسد الأحتفال الباناثيينيكي - للفنان فيدياس } \\
& \text { معبد البارثينون - اثينا - اليونان }
\end{aligned}
$$

كما تناول الفنان الأغريقي الجواد عندما قام بزخرفة التابوت المنسوب إلي الأسكندر الأكبر المحفوظ بمتحف أسطنبول شكل (r) ،"ويعتبر هذا التابوت من أجمل القطع الفنية

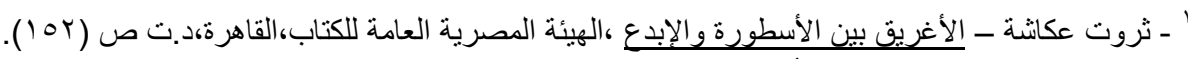

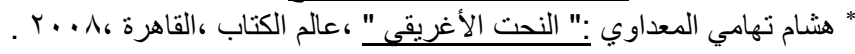




\section{الحصان في مجال النحت عبر العصور "دراسة تحليلية".}

العالمية في الفن الأورويي فهو منحوت من الرخام الأبيض الناصع ،ومزخرف بنحوت مجسمة من وجهاته الأريع ،وقد ظهر في الصورة منظر صيد الأسكندر للأسد ويراققه بعض الأمراء

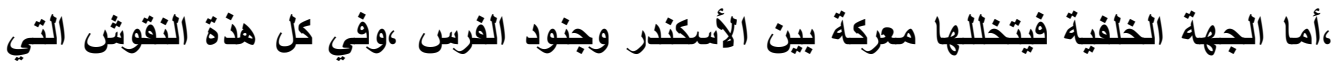
نري فيها الأثكال الطبيعة لجياد والحركات الواقعية نري سحن الأثخاص من الفريقين

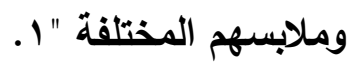

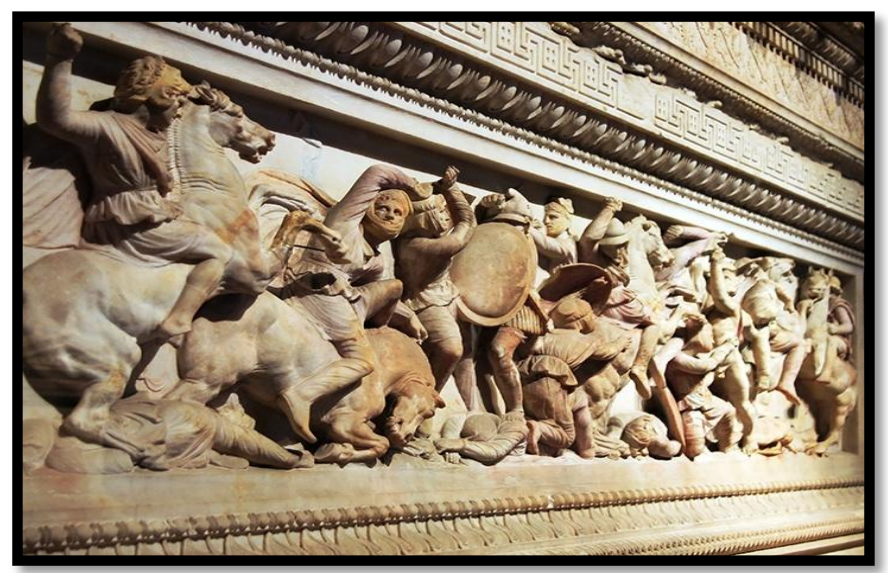

شكل(ץ) التابوت المنسوب إلي الأسكندر الأكبر - يجسد الأسكندر الأكبر في صيد الأسد راكبا حصانه

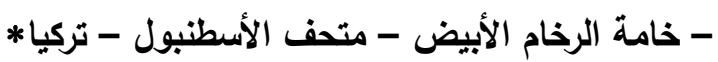

لم يقتصر الأمر علي تناول الحصان في الفن الأغريقي أو اليوناني علي الأعمال الجدارية أو بالنحت البارز ،بل عبر الفنان الأغريقي عن هذا الحيوان في الأعمال المجسمة

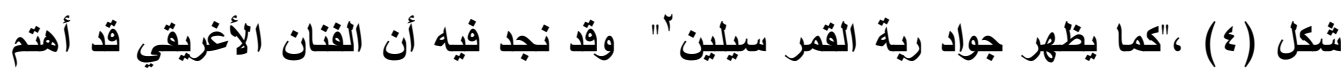
بالنواحي التشريحية عالية الدقة وكأنه يدرك بتوزيع الكتل العضلية والتهيكل العظمي لرأس الحصان ،وقد جسد الحصان وكأنه يصهل حيث فاتحا فمه كما نجد أيضا تلكك العيون الجميلة وما اجاده الفنان الأغريقي بإخراج تللك التفاصيل بصورة رائعة . 
الحصان في مجال النحت عبر العصور "دراسة تحليلية".

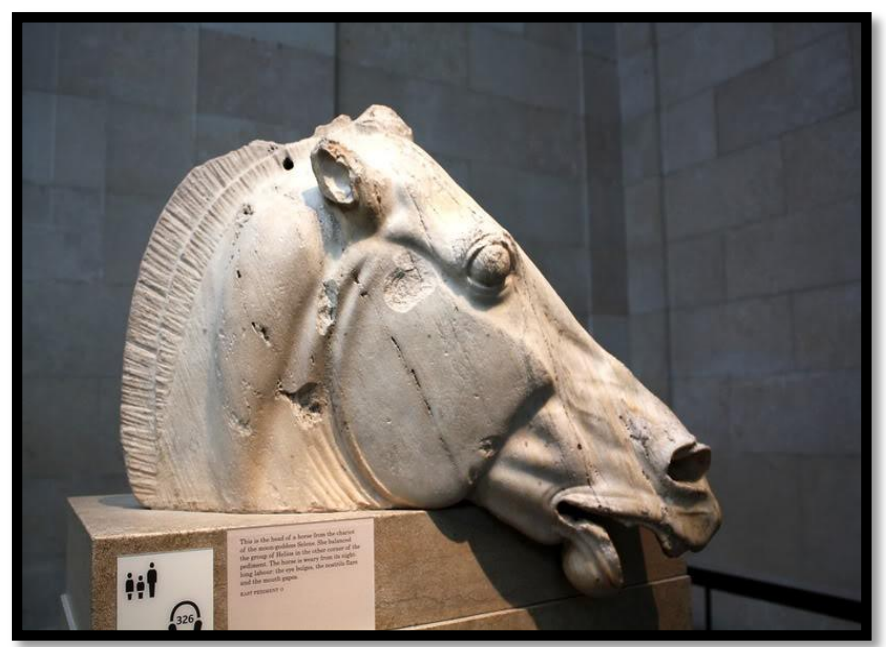

$$
\begin{aligned}
& \text { شكل ( ) تمثال جواد سيلين - وجهة مثلثة - البارثينون } \\
& \text { ^r ق ق.م - المتحف البريطاني }
\end{aligned}
$$

وقد أبدع الأغريق في نحت الحصان شكل (0) ،حيث أنه ذلك الحيوان الذي كان مشاركا في جميع المعارك والحروب التي خاضها اليونانين أو الأغريق في ذلك الوقت ،وكان

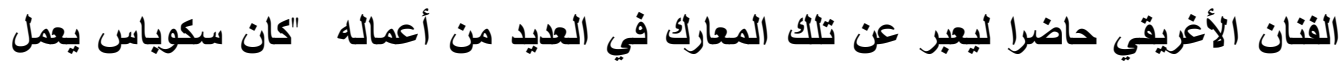
في ثلاثة أعمال نحتية معمارية في النصف الأول من القرن الرابع ق.م معبد أرتيميس في المي أفسوس ،ومعبد أثنيا في تيجاي ،وضريح هاليكارناسوس ،وقد تناول سكوياس معارك الأغريق

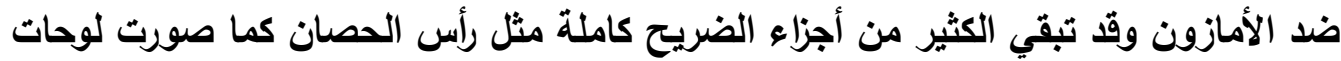
النحت عنف المعركة والتكوين يتسم بحرية الحركة التي تعكس عنف المعركة وقد أظهر النحات سيطرته علي تشريح أجساد شخوص النحت في أوضاعهم المختلفة "' ،وقد أتقن بالفعل النحات سكوياس في نحت حصان ضريح هاليكارناسوس الذي جسده رافعا عنقه مع إلتفاف بسيط للرأس وكأنه ينظر للأسفل . 
الحصان في مجال النحت عبر العصور "دراسة تحليلية".

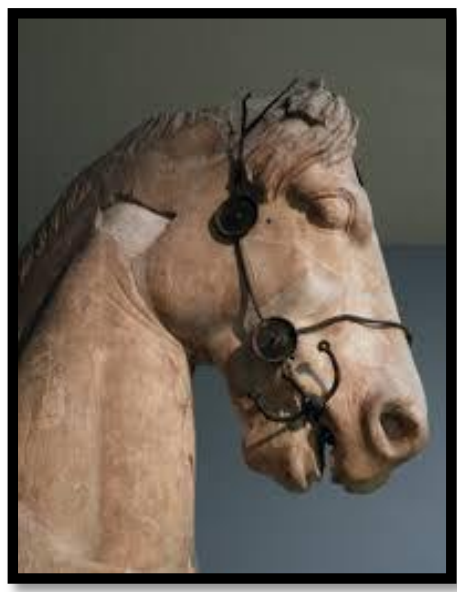

شكل (0) تمثال للحصان - ضريح هاليكارناسوس - للنحات سكوياس

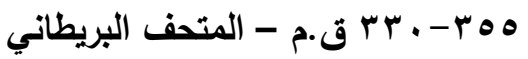

كما صورث الأفاريز مشاهد من حرب طروادة واحدة من أكبر المعارك التي خاضها اليوناتين حيث تظهر مشاهد العربات الحربية والفرسان والخيول التي جذبث أنتباه كل من يشاهدها والتي زخرفت الخزانة شكل (؟). "في أفاريز خزانة سيفينوس تعطي الخيول إحساسا مفعما بالحياة ،وإحساس الشخوص في الفراغ وتأثيرات زخرفية " 1 ـ

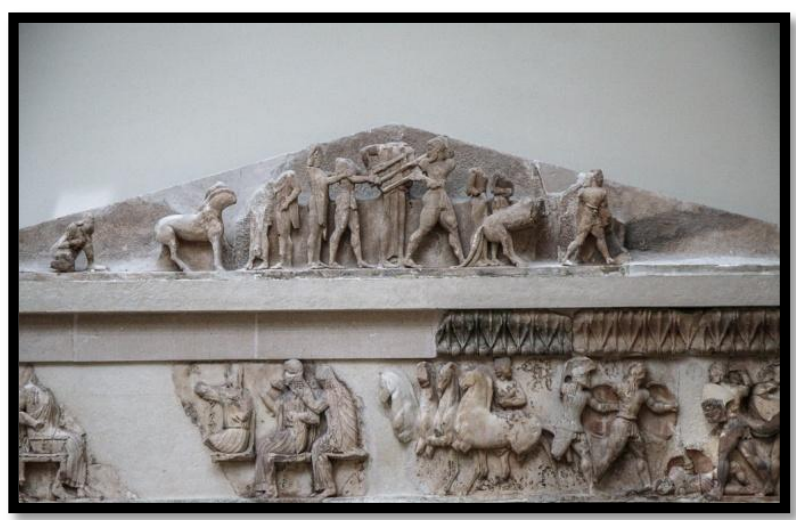

شكل (7) تحت بارز - حرب طروادة - أفريز خزانة سيفينوس حوالي · به - هץ ه ق.م - المتحف البريطاني 
ثالثاً :الحصان في الحضارة الروماني : الحئي إن الحضارة الرومانية كاسابقتها اليونانية قد زخرت بالعديد من الأعمال التي أحتوت

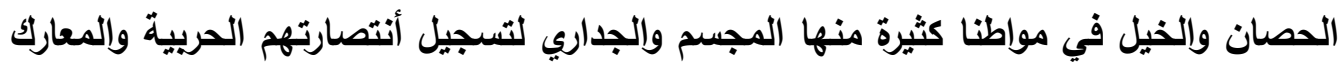
الكثيرة وقد عكست تلك الأعمال التقدم الفني الأي قد وصل إليه الرومان في تجسيد ذلك الكائن الفريد ،فقد تناول الرومان الحصان فنيا حينما قاموا بعمل تماثيل لهوّلاء الملوك والأباطرة ورجال الحكم في الحضارة الرومانية ،حيث نجدهم في هيئة فرسان قد أعتلو الخيول ومنها تمثال الأمبراطور (ماركورأوريليو ) وهوتمثال ضخم يمثله الفنان وهوممتطيا جواده شكل (V) ،"وهو مصنوع من البرونز ومقام وسط ميدان الكامبيتول المشرف علي ميدان البندقية

في روما ،ويعتبر أول تمثال في العالم لفارس علي الجواد الم ال. ولذلك أتخذه الفنانون نمذجا للتماثيل التي أقيمت لملوك وعظماء القارة العجوز وفي عصر النهضة والعصور الحديثة قريبا ،وقد أمتلأ هذا التمثال بالكثير من التفاصيل حيث ذلك السرج الجميل البديع والأنيق وقد أعطان الفنان الروماني حسا جماليا وكأنك تري الحصان متقدما إلي الأمام رافع رجله اليمني ومرتكزا علي ثلاثة أرجل وقد نجد أيضا الرجلين الخلفيتين واحدة منها الرجل اليسري تثقدم علي اليسري مع وجود الفارس شامخا مع ألتفاف رأس الحصان ناحية اليسار قد أعطت جمالا تثريحيا وزادت من الجمال التشكيل الفني للعمل

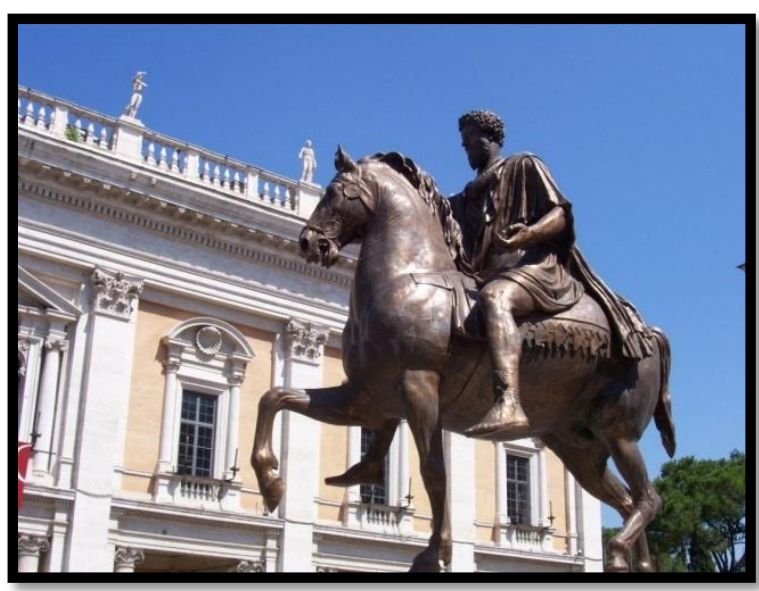

شكل (V) تمثال الأمبراطور "ماركو أوريليو: - ميدان الكامبيتول

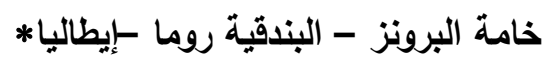

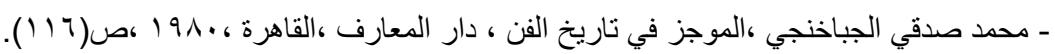

* http://europeanhistory.about.com/od/europeasawhole/a/histmyths5.htm 
ضمت أيضا النقوش الجدارية بطريقة النحت البارز تجسيد الحصان في الكثير من الأعمال فقد زينت أقواس النصر التي كان يقوم بتشيده الفنانين بأمر من ملوكهم وأباطرتهم أنتصارتهم وأنجازاتهم العديدة شكل (^).

"ولقد جرت عادة الرومان علي إقامة أقواس النصر للإثشادة بخاتمة الحملة العسكرية مظفرا تسفر عن إخضاع إحدي القبائل النائية أو ضم أحد الشعوب المتحضرة إلي فلتك الإمبراطورية الرومانية ،فشيد الإمبراطور تيتيوس (1-V9 منه عند عودته مكللا بالنصر علي رأس جيشه يجر وراءه صفا طويلا من أسري الحرب ومن العريات التي تحمل الأسلاب والغنائم العسكرية بينما يدوي في أذنيه تصفيق الملايين المهللين بعودته مظقرا • وقد سجلت إحدي لوحات النقوش البارز علي أحدي الجدارين الداخلبين للقوس مشاهد الإمبراطور تيتوس عقب انتصاره في فلسطين وهو واقف فوق مركبته ضمن موكبه كبير تتقدمه الإله "روما" وتتبعه جماعات من أعضاء الثيوخ الرومان ونواب الثعب في فئ

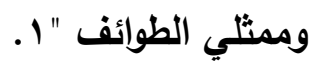

فإذا نظرنا للعمل النحتي هذا نجد أن الفنان الروماني قد نجح في تجسيد الحصان بصورة عالية الاقة ،وقد ظهر ذلك في إبرازه للعضلات والنواحي التشريحية للحصان ،حيث تلك الأفخاذ القوية الممتلأبالكتل العضلية الجميلة ،وكذلك صدر الحصان والعضلات الموجوده أيضا في رأسه .

لم يكتف القنان الروماني بذلك فقط داخل هذا العمل من قيم وعناصر نحتية بل أستغل تقتية النحت البارز شبه كامل الأستدارة كتقتية تمكنه من عمل إيقاع حركي قمة في الروعة فقد نجد أريعة من الحصان في هذا المشهر جميعهم الرجل اليمني لهم مرفوعه معطيتا للعمل

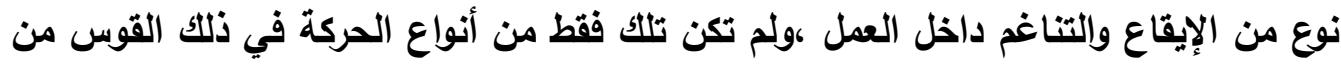
خلال الحصان ،حيث تلك الرؤوس المختلفت الأتجاهات وحركة فم الخيول المختلفة وكأنها تصدرا أصواتا صهيلا جليلا معطيا بذلك الفنان روحا لتلك الجدارية الرائعة . 
الحصان في مجال النحت عبر العصور "دراسة تحليلية".

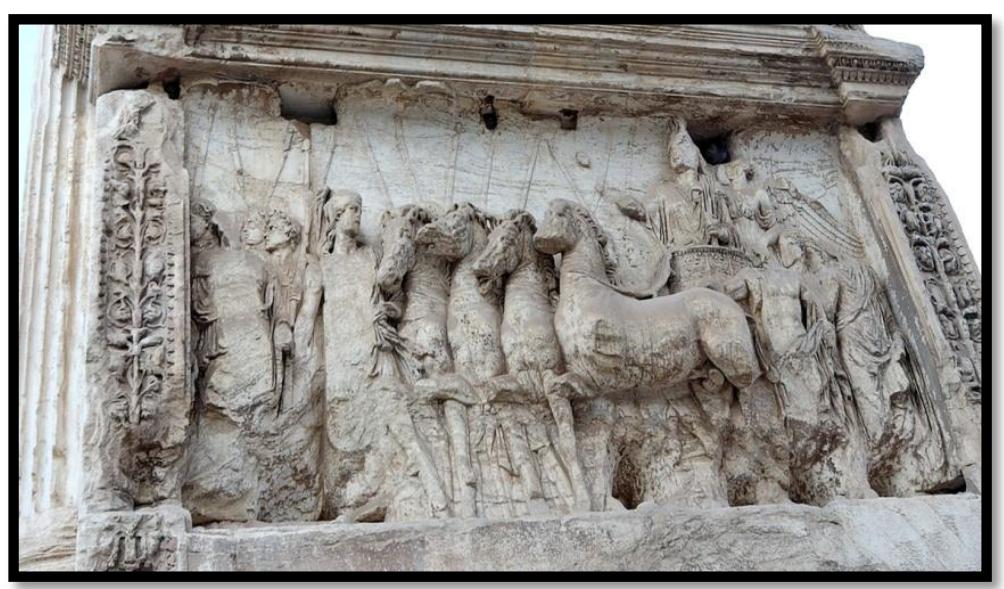

شكل (^) قوص نصر تيتوس - الإلة "روما" تتصدر مجموعة من الخيل مركبة النصر الأريعة -

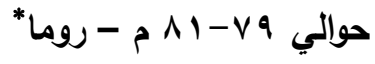

لم يقتصر ظهور الحصان أو الخيل في أقواس النصر والحروب فقط بل في مشاهد

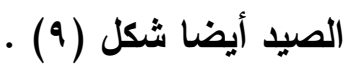

" وقد أخذت مشاهد الصيا والطراد ابتداء من عهر هادريانوس تفسح لنفسها مكانا فوق لوحات النقش البارز والتوابيت والفيسفساء ولوحات التصوير ، وكذلك مشاهد تقديم

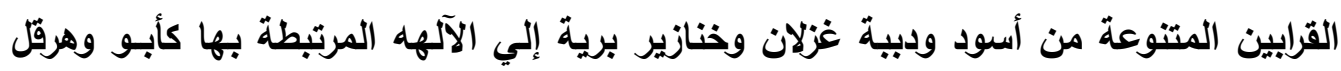
وديانا . 'المزين وينظر إلي ذلك العمل نرا أن الحصان يظهر في وضع الركض القوي والتسارع مع تلك

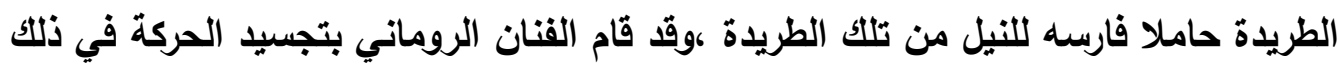
العمل عن طريق رفع الفرس لقائمتيه الأماميتين مع تأخير القائمتين الخلفيتين قليلا للوراء وكأنه الركض العالي ملاحقا بالخنزير مع تحريك رأس الحصان قليلا في أتجاه الخنزير معطيا نوعا من أنواع الحيوية داخل هذا العمل ،مع فتح فم الحصان الثالث ليعي مؤثرا وإيحاءا بالصوت أو التنفس الثدايد من مشقت المطاردة والجري القاس . 
الحصان في مجال النحت عبر العصور "دراسة تحليلية".

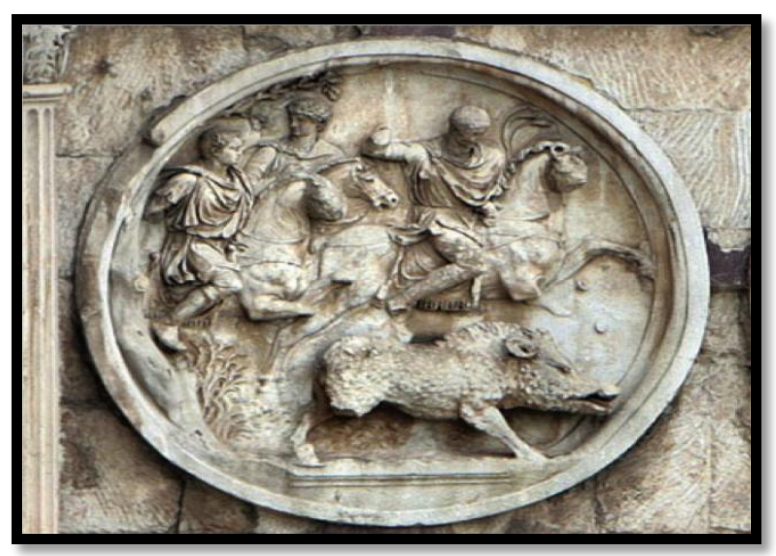

شكل (9) قوس نصر قسطنطين - من عهز هادريانوس تمثل تراجان يصيد الخنزير البري - بروما إيطاليا

رابعاً :الحصان في عصر النهضة والعصر الحليث :

تعدد ظهور الحصان في الكثير من الحضارات حتي وصل إلي العصر الحديث إلي أن وصلت إلي عصر النهضة حيث تعددت الأعمال الفنية التي ضمت الحصان ،في ذلك الوقت "ظهرت في مجتمعات البلاد الأورويبة في أواخر القرون الوسطي حركات متطورة في العلوم والقنون والآداب وكاتت نقطة البداية في الأهتمام بهذه الحركات الجديدة في إيطاليا "'،ومن أهم فناني عصر النهضة القنان العظيم ليوناردو دافنشي ،ولقد أهتم ليوناردو دافنشي الاني بالحصان أهتماما كبيرا ومميزا عن غيره من فناني عصر النهضة ،لما لهذا الحيوان الجميل

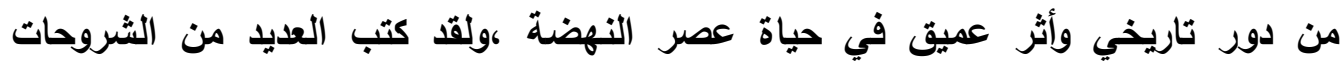
والتعليقات حول تشريح الحصان ومكانة هذا الحيوان النبيل علي أنه جهاز عضوي حي ويحوي ما وراء جلده عوالم مجهولة ومتعددة ،ومعني أن يتتاوله ذلك الفنان الكبير في أعماله برهان علي قيمة الحصان الجمالية والتشريحية شكل ( • ()،"ققا رسم عشرات التخطيطات للشكل الخارجي لهذا الحيوان ومن جوانب متعددة وخاصة الأرداف والصدر ،والأقدام الأمامية والخلفية ،كما رصد هذا الجسم بإيقاعات الخطوط المتكررة الدقيقة ،لتمثيل القراءة الأولي للعين البشرية ،بمخيلتها وصلابتها وتوازنها وتتاسبها ،محكومة بمهارات مقتدرة سعي الفنان

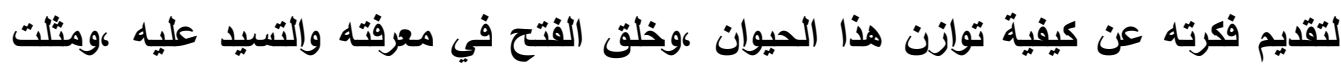

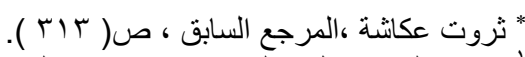

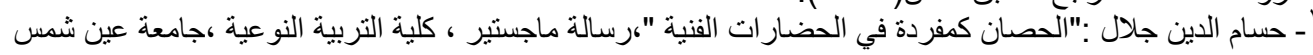
. (1.0) (1..9، 
هذة المجموعة من التخطيطات الدراسات الأولي الأولية للوحته التي انجزها فيما بعد عن

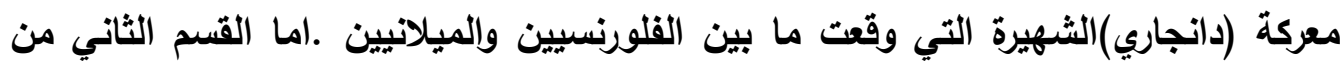
التخطيطاته عن الحصان فقط أرتبط مباشرة بالنسيج الداخلي للعضلات ذات الخطوط المستقيمة والمنحنية والمتركبة الواحدة علي الأخري بصناعة فنية تتيح تحليل الثكل الحقيقي لتركيب كتلة الجسم تحليلا يحوي علي مزيدا من الفهم في تبلور الفراغات والأمتلاءات

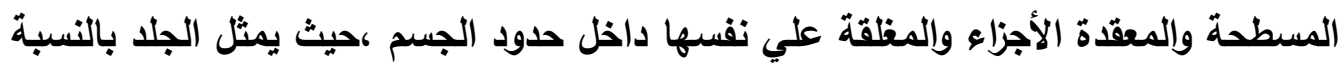
له الحاجز ما بينها ويبن الروئة الإنسانية ولقد عالج ليوناردو هذه النواحي التشريحية لعضلات هذا الحيوان وكأنها مشكلة تقتضي حلا يؤدي إلي معرفة جديدة تدعم العمل القني وترسي له تقاليا حرفية مهنية تساعد الروية الحية الخاصة بالعين والعقل لذلك الشكل الحقيقي لهذا الحيوان تحليلا يحوي من الفهم العلمي ". عصر النهضة من العصور التي تناولت الحصان بصورة قوية وشناملة في مجالات فنية متنوعة وكثيرة فكان ليوناردو دافنشي من أواءل الفنانين الذين تناولو الحصان في أعمالهم كما ذكرنا ذلك ولم يتوقف الأمر علي ليوناردو دافنشي بل هناك غيره وعلي سبيل المثال الفنان العظيم أندري ديل فيروكو والذي جسد الحصان في عمله الشهير "بارتليموكوليون" "شكل (1 1 )،قتد مثل
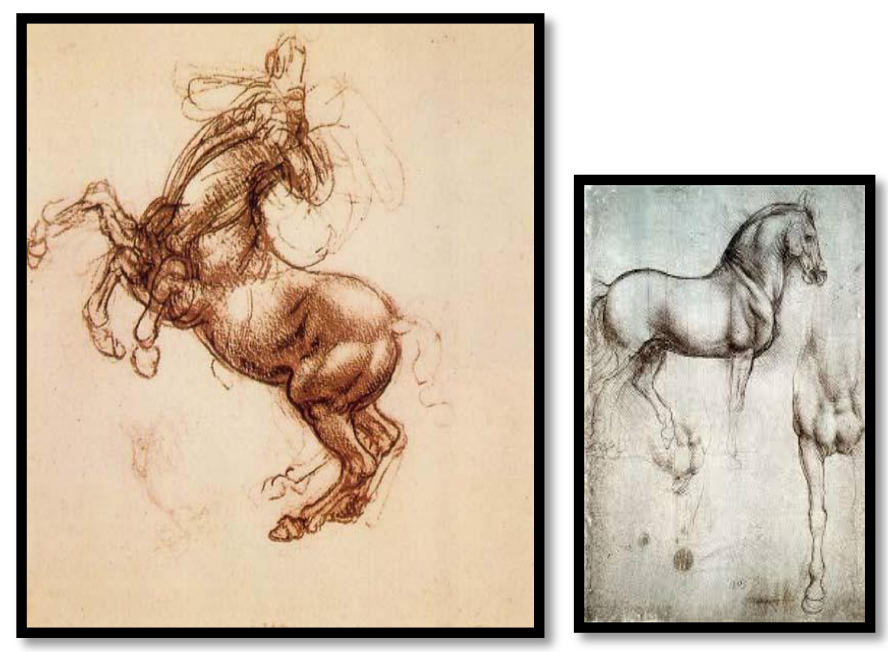

شكل (• 1) تخطيطات عن الحصان تمثل القيم التشريحة للحصان وقيمه الجمالية

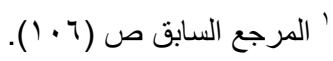


"ليوناردو دافنشي*

وجسد الشجاعة والأقدام الذي عرف عنه هذا القائد ومن الواضح تأثر ذلك الفنان بالقائد العظيم هذا وكما نعلم أن فيروكو هو أحد تلاميذ دوناتلو وأيضا قد تأثر بأستاذه فنجد وحه التثابه بينه ويين تمثال البطل جاتاميلا ووحه التثابه في الحركة والأسلوب . "فنجد هنا الجواد مرتكزا علي ثلاثة أرجل ورافع الرجل اليسري الأمامية ،وفي الرجلين

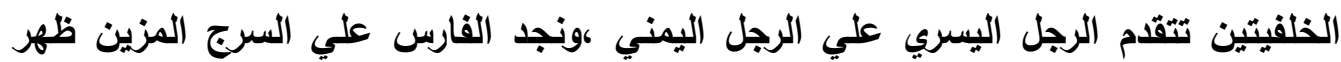
الحصان يرتدي حلته الحربية وعلي رأسه خوذة ويمسك بيده اليمني ،وكذلك حركة التفافه في رأس الفرس ناحية اليمين أيضا ،كما نجد جذع الفارس في وضع رأسي علي جذع الفرس الذي يبدو في وضع أفقي ،ونجد في رقبة الفرس قصيرة وغليظة ،ويتضح في التمثال أهتمام الفنان بدراسة العضلات والحركات محاكيا الطبيعة في أدق تفاصيلها ،كما نحس بالبنائية

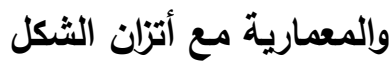

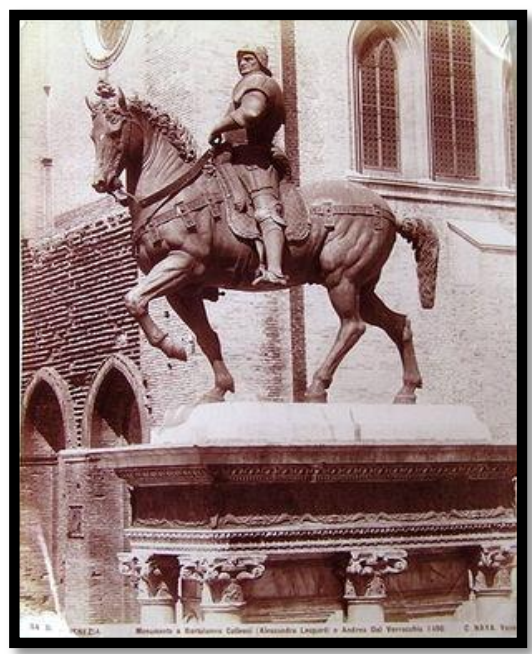

شكل (1 1 (1)تمثال القائد "بارتليموكوليون " - للقنان أندري ديل فيروكو

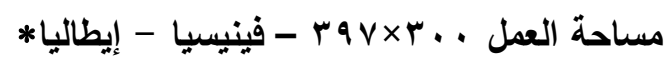

وقد حضر الحصان في فن الباروك في القن السابع عشر،ويطلق مؤرخو القنون كلمة

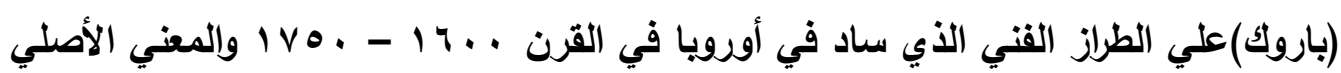




\section{الحصان في مجال النحت عبر العصور "دراسة تحليلية".}

لهذة التسمية مصدرها أسباني في الغالب باروكو وتطلق علي اللؤلؤ المشوة الغير منتظم الأستارة ،ولقد أستمد هذا الوصف للتعبير عن الفنون المخالفة للتقاليد السائدة والناهضة

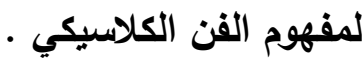
ولقد أغري شكل الحصان وجمال خطوطه وحركاته فناني الباروك ،فتناولوهفي موضوعاتهم النحتية عندما قاموا لعمل تماثيل للملوك أو للشخصيات البارزة كفرسان معللين

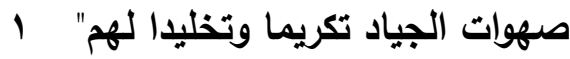
وقد أستخدم الفنان الإيطالي الكبير جان لورنزو برنيني الحصان الكيان في كثير من أعماله الفنية الكثيرة والمتنوعة ونذكر منها ذلك العمل الذي قام به الفنان بنحت تمثال للملك لويس فئن

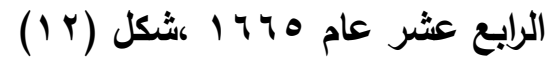
ويظهز في هذا التمثال حركة شب الحصان مرتكز علي رجليه الخلفيتين ورافعا رجليه الأماميتين معا ،كما نجد حركة ألتفافه ناحية اليمين في رأس العصان ونجد الملك علي ظهره يلتفت برأسه وجذعه ناحية اليمين نري ذراعه الأيمن منفردا أو معلقا في الفضاء

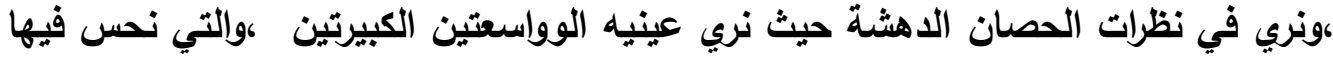

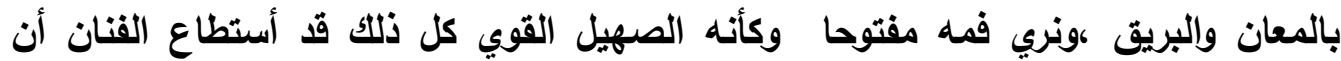

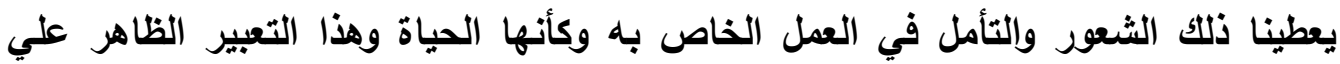
الحصان يختلف تماما عن التعبير الظاهر علي وجه الملك والذي نري به الحزم والأصرار والقوة ،هنا طراز الباروك روح الباروك جمال فن وعصر الباروك في المبالغة لأظهار الديناميكية والحركة فقد أتقن وأبدع الفنان في أظهار الحركة بصورة دقيقة جدا دون نسيان

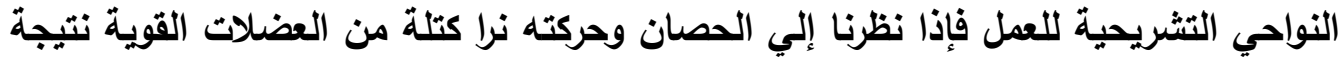
الحركة ،وأذا نظرنا إلي تلك الخطوط في الثعر الخاص بالحصان المموج الطويل الذي نراه خلف رقبة الحصان وفي الزيل ..حركة قد نتجتها تلك الغطوط الحلزونية الغير منتظمة الأستدارة والتي تخالف التقاليد السائدة لمفهوم الكلاسيكية . 
الحصان في مجال النحت عبر العصور "دراسة تحليلية".

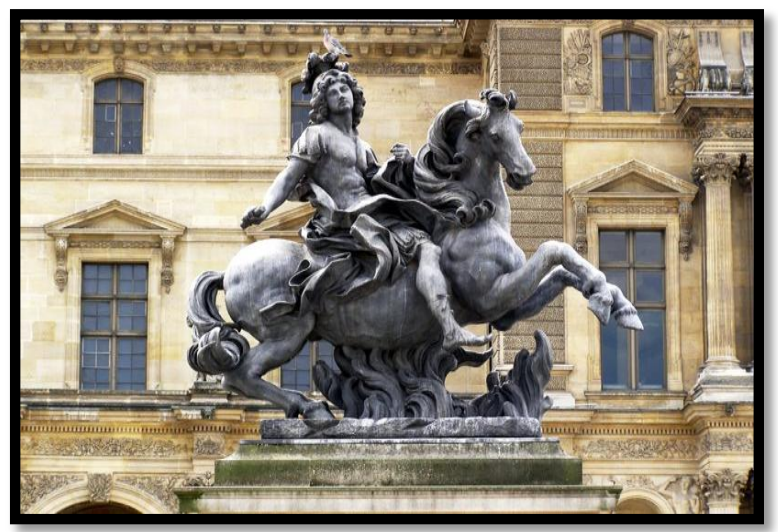

شكل (r I)تمثال الملك لويس الرابع عشر - القنان الإيطالي جان لورنزو برنيني

$$
\text { حدائق فرسيليز - فرنسا }
$$

أكدت نتائج الدراسات المرتبطة بالبحث والتي تم تحليلها وتوصل الباحث من خلالها

1 - أهتم العديد من الفنانين عبر العصور بعنصر الحصان : - أُتخدم الحصان عبر العصور المختلفة بأشكال متتوعة مابين البارز والمنخفض البروز والمتوسط البروز وذللك في العصر المصري القديم • - تثاوله الفنان الأغريقي والروماني وقام بالتركيز على الجاتب التشريحي مع دراسة بالغة بأسلوب التحث البارز (شديد البروز وشبه كامل الأستدارة) والتي تؤكد براعة وقرة الفنان والنحات . - وتتاول الفنان المعاصر الحصان بالعديد من الأساليب التشكيلية المتنوعة مابين واقعي وتجريلي وشبه تجريدي ويأساليب تثكيلية نحتية متتوعة تُبز قدرة ويراعة القنان المعاصر وروئيه المتميزة من خلال فن النحت . ץ- أن جمال ورشاقة حركة الحصان كانت مرجع للقنانين عبر العصور يُستلهم من خلاله أعمال فنية عظيمة خالدة ما زالت باقية تأكد علي عظمة الله سبحانه وتعالي في قرته في خلق هذا الكائن المبهر. 


\section{الحصان في مجال النحت عبر العصور "دراسة تحليلية".}

r- وأن التغيرات التشريحية التي تطرأ علي شكل الحصان عذدما تتغير أوضاعه الحركية

نتيجة الصهيل والركض القاسي يمكن توظيفها في الأعمال الفنية النحتية المختلفة . ع - أن رشاقة الحصان في امتداد الرقبة بثكل انسيابي في وضع منحني لتخرج الرأس بكل رشاقة في شكل مخروطي حيث أنها تعطي أبعاد جمالية وتثريحية تعبيرية عالية الدقة.

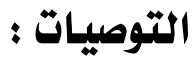

$$
\text { يوصي الباحث ب :- }
$$

1 - إلقاء الضوء علي الدراسة التثريحية لما لها من أثثر واضح في تعليم الفنون وإبراز القيم

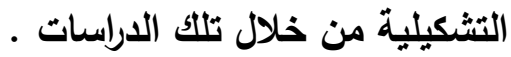

r- الإهتمام بتدريس النحت المصري القديم والروماني واليوناني والعصر الحديث التي تناولت الأعمال النحتية بدراسة تثريحية متميزة ، لتثري العطلية التثريسية باعتبار تلكت

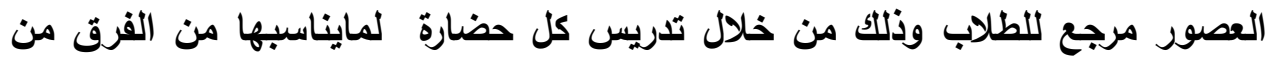

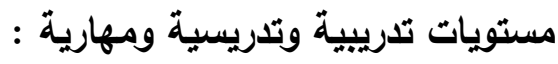

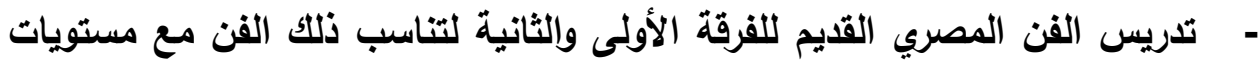

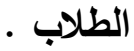
- تلدريس الفن اليوناني والروماني للفرقتين الثالثة والرابعة وذلك بسبب أن الفن

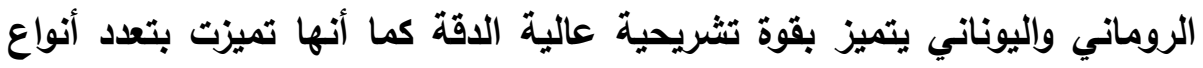
النحت وخاصتاً النحت الجداري البارز الذي ظهر بصور عديدة منها الثديد البروز - وشبه كامل الأستدارة - وكامل الأستدارة الملتصق بالسطح وهذه الأنواع مناسبة لتلك الفرق التصريسية . - الفن الحديث .. ذلك النوع مناسب جداً لتدريسه للمراحل المتقدمة كالفرقة الريعة لما يحويه هذا النوع من مستوى فكري وإبداعي قوي . r- تناول المخلوقات التي تتوافر فيها نواحي تثريحية عالية الدقة في تدريس النحت بكليات

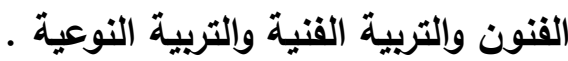




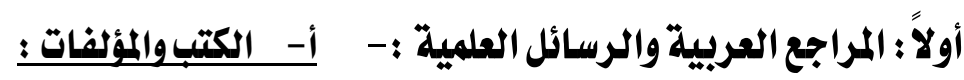
1- ثروت عكاشة : الأغريق بين الأسطورة والإبدع ،الهيئة المصرية العامة

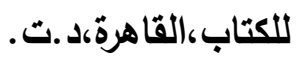
ب- ثروت عكاشة :الفن الروماني ، الهيئة المصرية العامة للكتاب ، القاهرة ،د.ت.

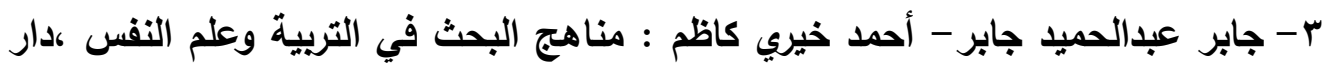

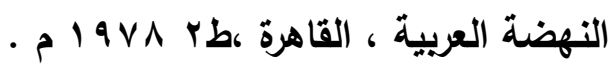

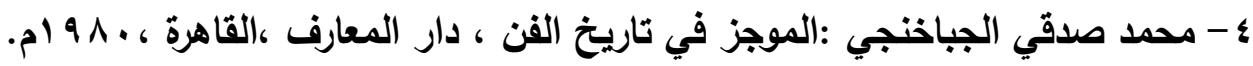

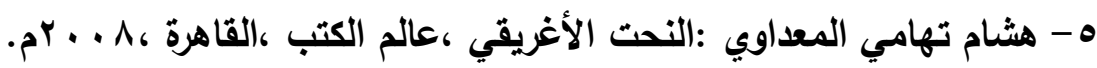

\section{ب- بـ الرسائل والأبحاث العلمية:}

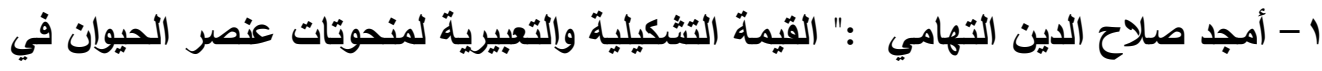
اتجاهات الفن الحليث "،رسالة ماجستير ، كلية التربية الفنية، جامعة حلوان ، القاهرة ، .01999 r- حسام الدين جلال :"الحصان كمفردة في الحضارات الفنية "رسالة ماجستير ، كلية

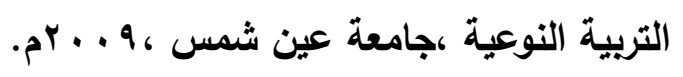
r- مجدي عبدالسلام محمد :"مناظر القتال وحصار لمدن في النقش الأثشوري في عصر

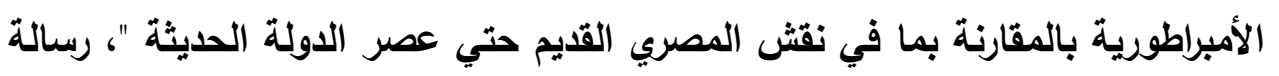

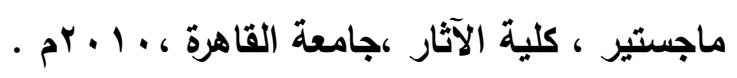

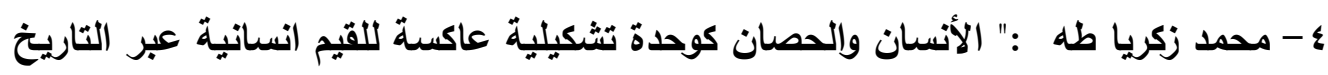

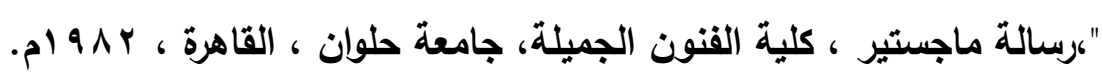

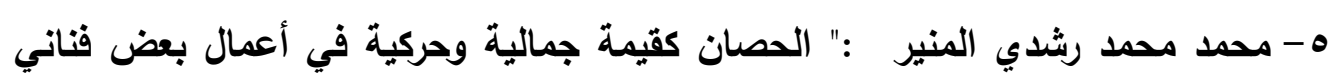

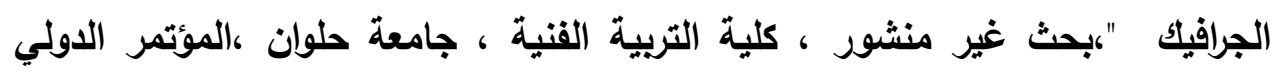

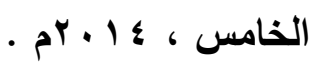


الحصان في مجال النحت عبر العصور "دراسة تحليلية".

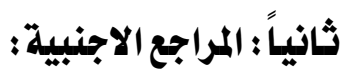

1- Marshll Gavendish:"Apopular History of the Art"London,Marshall Gavendish ,Book ,Ltd,1984.

ثالثاً :شبكة المعلومات الإنترنت :

2- http://europeanhistory.about.com/od/europeasawhole/a/histmyths5.htm

3- http://www.wikiwand.com/

4- https://artplastoc.blogspot.com.eg/2011_08_01_archive.html 